\title{
Vinyl Dihydropyrans and Dihydrooxazines from Cyclizations of Catalytic Ruthenium Carbenes Derived from Alkynals and Alkynones
}

\author{
Fermín Cambeiro, Susana López, Jesús A. Varela, Carlos Saá*
}

Dedication((optional))

\begin{abstract}
A novel synthesis of 2-vinyl dihydropyrans and dihydro1,4-oxazines (morpholine derivatives) from alkynals and alkynones has been developed. The cyclizations require a mild generation of catalytic ruthenium carbenes from terminal alkynes and (trimethylsilyl)diazomethane followed by trapping with carbonyl nucleophiles. Mechanistic aspects of the new cyclizations are discussed.
\end{abstract}

$\mathbf{S}_{\text {ix-membered oxygenated heterocycles, pyrans, are privileged }}$ structures for a large number of natural products and biologically active molecules. ${ }^{[1]}$ Their partially hydrogenated derivatives, e.g. 3,4-dihydropyrans, ${ }^{[}{ }^{2}$ ] $]$ are interesting precursors for tetrahydropyrans ${ }^{[3]}$ and glycals, ${ }^{[4]}$ which are useful building blocks, particularly in carbohydrate chemistry. ${ }^{[5]}$ Two main synthetic strategies have been exploited for the efficient preparation of 3,4dihydropyrans and their 4,5-benzoderivatives: (a) hetero DielsAlder (HDA) reactions of aldehydes and Danishefsky's diene, ${ }^{[6]}$ which afford the corresponding dihydropyran derivatives with high diastereo- and enantioselectivities; and (b) endo cycloisomerization of alkynols with catalytic metal vinylidenes (W, Rh and $\mathrm{Ru}$ ). ${ }^{[7]}$ Other attractive and useful unsaturated pyran derivatives, 2vinyltetrahydropyrans, have been accessed through alkyne-, alleneor allyl-activated exo cyclizations using $\mathrm{Pd}$, Ir, $\mathrm{Au}$ and $\mathrm{Fe}$ catalysts. ${ }^{[8]}$ Although these methods have been very successful, they only allow the expeditious introduction of one valuable alkene functionality at a time in the pyran core. Herein we report a new, efficient and direct approach to difunctionalized 2-vinyl-3,4dihydropyrans $^{[9]}$ (a convenient substitution for the synthesis of natural pyrans) based on the cyclization of alkynals and alkynones

[*] Fermín Cambeiro, Dra. Susana López, Dr. Jesús A. Varela, Prof Carlos Saá

Departamento de Química Orgánica y Centro Singular de Investigación en Química Biológica y Materiales Moleculares (CIQUS)

Universidad de Santiago de Compostela

15782 Santiago de Compostela

Fax: (+)34-881815704

E-mail: carlos.saa@usc.es

Homepage: http://www.usc.es/gi1603/saa

[**] This work was supported by MICINN (Spain) [projects CTQ201128258, Consolider Ingenio 2010 (CSD2007-00006)] and Xunta de Galicia and the European Regional Development Fund (project CN2011/054 and EM 2012/051). F.C. thanks XUGA for a predoctoral contract.

Supporting information for this article is available on the WWW under http://dx.doi.org/10.1002/anie.201xxxxxx through catalytic Ru-carbenes formed in situ by the addition of (trimethylsilyl)diazomethane (Scheme 1). ${ }^{[10]}$ Cyclizations occurred under very mild conditions and usually gave good yields and excellent diastereoselectivities in short reaction times.

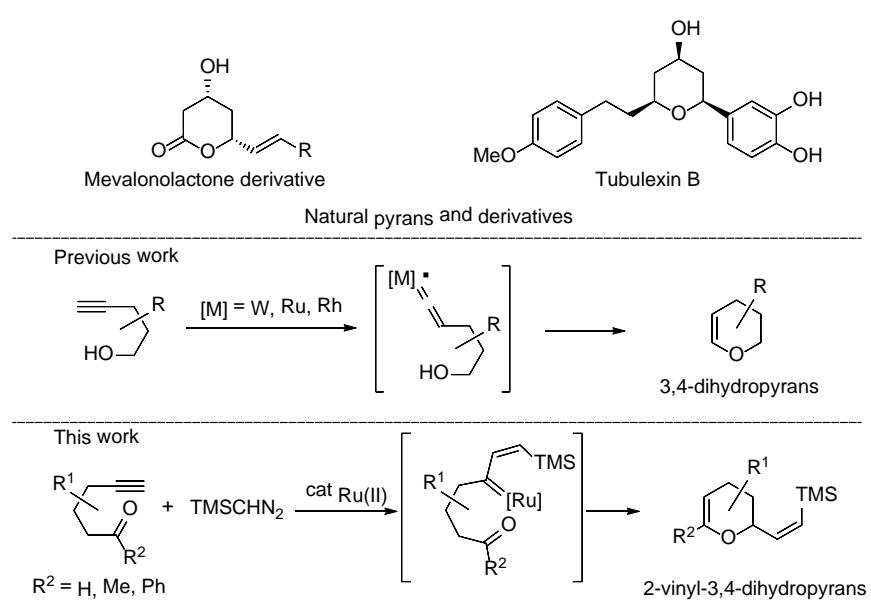

Scheme 1. Pyrans from metal-catalyzed heterocyclizations.

Initial coupling of alkynal 1a with $\mathrm{TMSCHN}_{2}$ using our reported conditions ${ }^{[11]}$ gave the cyclized product, 2-vinyl-3,4dihydropyran 2a, as the unique $Z$ isomer in good yield (65\%, Table 1, entry 1). ${ }^{[12]}$ Interestingly, changes in the electronic and steric nature of the $\mathrm{Ru}(\mathrm{II})$ catalyst on using [CpRuCl(cod)] did not affect the reaction yield but did influence the double bond geometry of the vinylsilane moiety (2a, Z/E 1:4, entry 2). Decreasing the catalyst loading (5 mol\%) while increasing the amount of TMSCHN 2 (2.4 equiv) gave the expected dihydropyran $\mathbf{2 a}$, albeit in a moderate yield (57\%, entry 3). The reaction yield remained unaltered on using a slight excess of $\mathrm{TMSCHN}_{2}$ (entry 4). ${ }^{[13]}$ Other polar aprotic solvents like acetone and dichloromethane gave lower yields of $\mathbf{2 a}$ with longer reaction times and, in addition, small quantities of vinyloxirane $3 \mathbf{a}$ as a mixture of $Z / E$ isomers (entries 5 and 6). Interestingly, while the primary alcohol $\mathrm{MeOH}$ gave a complex mixture of products (entry 7), use of the secondary alcohol $i$-PrOH allowed us to isolate dihydropyran $\mathbf{2 a}$ as a unique $Z$ isomer in good yield (71\%) in a short reaction time (entry 8 ).

Table 1. Optimization of Ru-catalyzed cyclization of alkynal 1a with $\mathrm{TMSCHN}_{2}$.

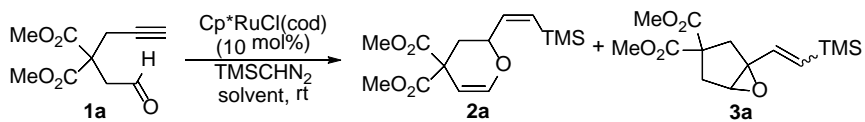




\begin{tabular}{cccc}
\hline Entry & $\mathrm{TMSCHN}_{2}$ (equiv) & Conditions & Yield 2a/3a (\%) ${ }^{[a]}$ \\
\hline 1 & 1.1 & $\mathrm{Et}_{2} \mathrm{O}, 1 \mathrm{~h}$ & $65 /-$ \\
$2^{[b]}$ & 1.1 & $\mathrm{Et}_{2} \mathrm{O}, 1 \mathrm{~h}$ & $68^{[\mathrm{cc} /-}$ \\
$3^{[\mathrm{d}]}$ & 2.4 & $\mathrm{Et}_{2} \mathrm{O}, 18 \mathrm{~h}$ & $57 /-$ \\
4 & 1.8 & $\mathrm{Et}_{2} \mathrm{O}, 1 \mathrm{~h}$ & $66 /-$ \\
5 & 1.8 & $\mathrm{Acetone}^{2}, \mathrm{~h}$ & $57 / 5$ \\
6 & 1.8 & $\mathrm{CH}_{2} \mathrm{Cl}_{2}, 5 \mathrm{~h}$ & $54 / 10$ \\
7 & 1.8 & $\mathrm{MeOH}^{2}, \mathrm{~h}$ & $-[\mathrm{e}]$ \\
8 & 1.8 & $i-\mathrm{PrOH}, 1 \mathrm{~h}$ & $71 / 6$ \\
\hline
\end{tabular}

[a] Isolated yields. [b] $\mathrm{CpRuCl(cod)}$ as catalyst. [c] Mixture of $Z / E$ isomers (1:4). [d] $5 \mathrm{~mol} \%$ of catalyst. [e] Complex mixture.

This encouraging result led us to explore the scope and limitations of the cyclization (Table 2). Alkynals $\mathbf{1 b}, \mathbf{c}\left(\mathrm{R}^{1}, \mathrm{R}^{2}=\right.$ $\mathrm{CH}_{2} \mathrm{OBn}, \mathrm{CH}_{2} \mathrm{OAc}$ ) bearing two $\mathrm{C}_{\mathrm{sp} 3}$ substituents in $\mathrm{C}-3$ also gave fairly good yields of the corresponding vinyldihydropyrans $\mathbf{2 b , c}$. Monosubstituted C-3 alkynals $\mathbf{1 d}-\mathbf{g}$ allowed us to study the diastereoselectivity of the cyclization. Thus, the $\mathrm{C}_{\text {sp2-substituted }}$ methoxycarbonyl alkynal $\mathbf{1 d}\left(\mathrm{R}^{1}=\mathrm{CO}_{2} \mathrm{Me}, \mathrm{R}^{2}=\mathrm{H}\right)$ cyclized to give dihydropyran $\mathbf{2 d}$ as a single syn diastereomer but, unfortunately, the yield was low. To our delight, $\mathrm{C}_{\mathrm{sp} 3}$-substituted benzyloxymethyl or acetoxymethyl alkynals 1e,f $\left(\mathrm{R}^{1}=\mathrm{CH}_{2} \mathrm{OBn}\right.$ and $\left.\mathrm{CH}_{2} \mathrm{OAc}, \mathrm{R}^{2}=\mathrm{H}\right)$ were smoothly converted to vinyldihydropyrans $2 \mathbf{e}, \mathbf{f}$ in good yields in a completely diastereoselective syn fashion. Owing to the critical role of C-4 oxygenated substituents in natural dihydropyrans with biological activity, ${ }^{[1]}$ we decided to evaluate the cyclization of 3silyloxyalkynal $\mathbf{1 g}(R)\left(\mathrm{R}^{1}=\mathrm{H}, \mathrm{R}^{2}=\right.$ OTBS $)$. To our initial surprise, oxygenated dihydropyran $\mathbf{2} \mathbf{g}$ was obtained in good yield but the diastereoselectivity was rather low in $i-\mathrm{PrOH}$ or $\mathrm{Et}_{2} \mathrm{O}$ (syn:anti 3.3:1 and 1.7:1, respectively). We believe that the oxygenated substituent in alkynal $\mathbf{1 g}$ might coordinate to the key ruthenium intermediate and, therefore, modify the diastereoselectivity (see Scheme 3). Even the more bulky 3-silyloxyalkynal $\mathbf{1 h}\left(\mathrm{R}^{1}, \mathrm{R}^{2}=\mathrm{H}\right.$, OTIPS) gave only a slightly higher diastereoselectivity of dihydropyran $\mathbf{2 h}$ (syn:anti $4: 1$ in $i-\mathrm{PrOH})$. Interestingly, the C-2 monosubstituted 2-propyl-5hexynal gave exclusively the 5-propyl-2-vinyl-3,4-dihydropyran 4 in moderate yield, thus showing the influence of the nature of the reacting conformer in the reaction course. ${ }^{[14]}$ Notably, cyclization of alkynal 1i, with substituents in C-3 and C-4, again leads to high levels of diastereoselectivity and gave rise exclusively to the syn vinyldihydropyran $2 \mathbf{i}$ in fairly good yield.

Chemoselectivity of the reaction was analyzed during cyclization of the difunctionalized enynal, 3-(prop-2-ynyl)hex-5enal, in which the major isolated product, vinylcyclopropane 5, derives from the cyclization of enyne ${ }^{[10]}$ against the minor dihydropyran $2\left(\mathrm{R}^{1}, \mathrm{R}^{2}=\mathrm{CH}_{2} \mathrm{CH}=\mathrm{CH}_{2}, \mathrm{R}=\mathrm{H}\right)$ from de cyclization of alkynal (3.5:1, $43 \%$ overall).

Table 2. Ru-catalyzed cyclizations of alkynals/alkynones $1(\mathrm{R}=\mathrm{H}, \mathrm{Me}, \mathrm{Ph})$ to 2 vinyldihydropyrans 2 .

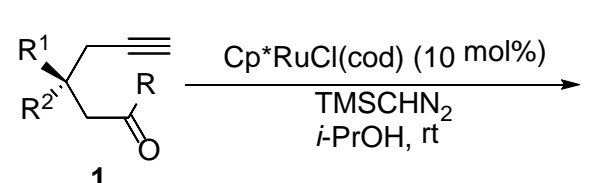

1

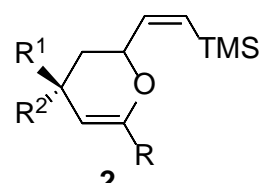

2

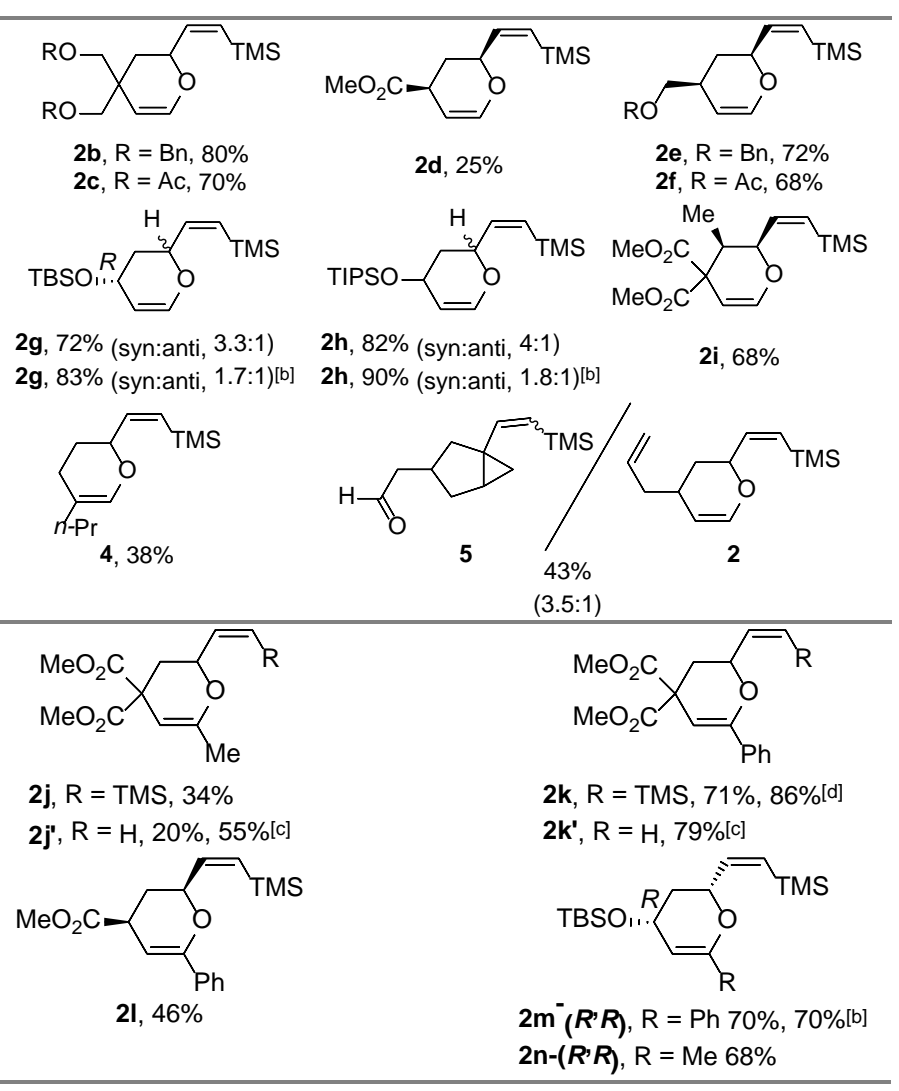

[a] Typical conditions: $\mathrm{Cp}^{\star} \mathrm{RuCl}(\mathrm{cod})$ (10 mol\%), $\mathrm{TMSCHN}_{2}$ (1.8 equiv), $i$-PrOH, rt, [1] $=0.15 \mathrm{M}$. [b] $\mathrm{Et}_{2} \mathrm{O}$ as solvent. [c] $\mathrm{MeOH}$ as solvent. [d] $\mathrm{CH}_{2} \mathrm{Cl}_{2}$ as solvent.

The cyclization of alkynones was subsequently explored. Initially, alkynyl methyl ketone $\mathbf{1} \mathbf{j}\left(\mathrm{R}^{1}, \mathrm{R}^{2}=\mathrm{CO}_{2} \mathrm{Me}, \mathrm{R}=\mathrm{Me}\right)$ was subjected to the typical reaction conditions in $i-\mathrm{PrOH}$ and this gave moderate yields of a mixture of vinyldihydropyrans $2 \mathbf{j}(\mathrm{R}=\mathrm{TMS})$ and $\mathbf{2} \mathbf{j}^{\prime}(\mathrm{R}=\mathrm{H})$. It was suspected that the enolizable ketone in $i$ $\mathrm{PrOH}$ could cause partial desilylation of $\mathrm{TMSCHN}_{2}$ and this, indeed, gave rise to the mixture of cyclized products. As a result, the reaction was also performed in $\mathrm{MeOH}$ and this gave exclusively the expected desilylated $\mathbf{2} \mathbf{j}$ ' in similar overall yield. ${ }^{[10]}$ By contrast, nonenolizable alkynyl phenyl ketone $\mathbf{1 k}\left(\mathrm{R}^{1}, \mathrm{R}^{2}=\mathrm{CO}_{2} \mathrm{Me}, \mathrm{R}=\mathrm{Ph}\right)$ cyclized more smoothly and cleanly than $\mathbf{1 j}$ in $i-\mathrm{PrOH}$ or $\mathrm{CH}_{2} \mathrm{Cl}_{2}$ to give exclusively the silylated dihydropyran $\mathbf{2 k}$ in fairly good yields. On the other hand, desilylated dihydropyran $\mathbf{2} \mathbf{k}^{\prime}$ could be obtained in very good yield when the cyclization was performed in $\mathrm{MeOH}$.

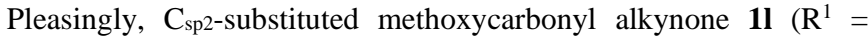
$\mathrm{CO}_{2} \mathrm{Me}, \mathrm{R}^{2}=\mathrm{H}, \mathrm{R}=\mathrm{Ph}$ ) cyclized to dihydropyran $\mathbf{2 l}$ as a single syn diastereomer in moderate yield as compared to the low yield of alkynal 1d. To our delight, enantiomerically pure silyloxy phenyl and methylketones $\mathbf{1 m}(R)$ and $\mathbf{1 n}(R)\left(\mathrm{R}^{1}=\mathrm{H}, \mathrm{R}^{2}=\right.$ OTBS $)$ cyclized diastereoselectively to give the corresponding syn vinyldihydropyrans $\mathbf{2} \mathbf{m}(R, R)$ and $\mathbf{2} \mathbf{n}(R, R)$ in rather good yields. Remarkably, steric factors in the most stable conformer of the key $\mathrm{Ru}$ intermediate probably control the diastereoselectivity of the cyclization process ( $\mathbf{2 m}$ or $\mathbf{2 n} v s \mathbf{2 g}$ ).

Conformationally locked bicyclic morpholines (dihydro-1,4oxazines), e.g. oxabispidines and 8-oxa-3-azabicyclo[3.2.1]octanes, have been shown to display a range of biological properties that have attracted interest in the pharmaceutical industry. ${ }^{[15]}$ Typically, derivatives of 2-vinyl-3,4-dihydro-2H-1,4-oxazines 7 have been used as pivotal structures to access therapeutic agents. A new synthetic strategy to these relevant structures based on Ru-catalyzed cyclization of $N$-tethered alkynals and alkynones $\mathbf{6}$ has been developed (Table 3). 
Table 3. Ru-catalyzed cyclizations of $N$-tethered alkynals/alkynones 6 to 2vinyldihydrooxazines 7 . ${ }^{[a]}$

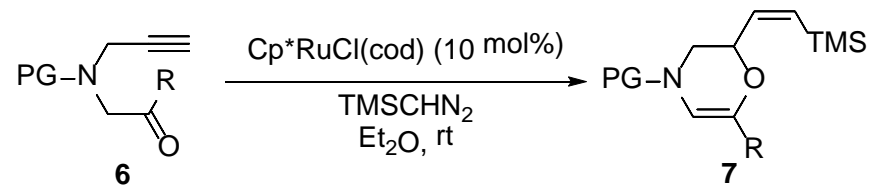

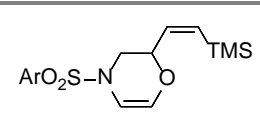

$7 \mathrm{a}, \mathrm{Ar}=\mathrm{Tol}, 58 \%$

$7 \mathrm{~b}, \mathrm{Ar}=\mathrm{Tis}, 57 \%$

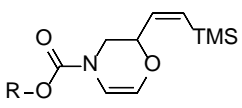

7c, $\mathrm{R}=t-\mathrm{Bu}, 58 \%$

$7 d, R=B n, 55 \%$

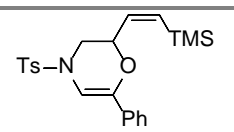

$7 e, 87 \%$ [a] Typical conditions: $\mathrm{Cp}^{*} \mathrm{RuCl}(\mathrm{cod})$ (10 mol\%), $\mathrm{TMSCHN}_{2}$ (1.8 equiv), $\mathrm{Et}_{2} \mathrm{O}, \mathrm{rt}$, $[6]=0.15 \mathrm{M}$.

Either $N-\mathrm{SO}_{2} \mathrm{Ar}$ protected alkynals $\mathbf{6 a}, \mathbf{b}$ or $N$-Boc and $N$-Cbz protected alkynals $\mathbf{6 c , d}$ were smoothly converted into 2vinyldihydrooxazines $\mathbf{7 a - d}$ in moderate-to-good yields under the typical reaction conditions ( $\mathrm{Et}_{2} \mathrm{O}$ as solvent). To our delight, $\mathrm{N}$ $\mathrm{SO}_{2} \mathrm{Ar}$ protected alkynone 6e was successfully transformed into the corresponding 2-vinyl-6-phenyldihydroxazine $7 \mathbf{e}$ in excellent yield. ${ }^{[16]}$

In an effort to gain further insights into the cyclization process, a series of deuterium labeling experiments were conducted. Alkynal [D]-6a', with a deuterium atom in the terminal alkyne, was transformed into the corresponding 2-vinyldihydroxazine [D]-7a' with deuterium located in the expected $\beta$-vinylic position (Scheme 2, eq 1). Similarly, alkynal [D]-6a" with deuterium in the aldehyde group gave the corresponding 2-vinyldihydroxazine [D]-7a" in which the deuterium was in the expected $\alpha$-enolether position (Scheme 2, eq 2). Two experiments were performed to evaluate the influence of a protic solvent during the reaction course. When the reaction of alkynal 1a was carried out in $i$-PrOD, the deuterium was incorporated selectively (75\% deuterium incorporation) into the $\alpha$ vinylic position of [D]-2 $\alpha \mathbf{a}^{\prime}$ (Scheme 2, eq 3), whereas reaction of alkynal [D]-1a' gave dihydropyran $[\mathbf{D}]-\mathbf{2}_{\boldsymbol{\beta}} \mathbf{a}$ ' in which the deuterium remains in the expected $\beta$-position without any deuterium scrambling with the protic solvent (Scheme 2, eq 4). These last two results show the crucial role of the solvent during the cyclization process. Finally, cyclization of dideuterated alkynone [D]-6e in $\mathrm{Et}_{2} \mathrm{O}$ gave the dideuterated 2-vinyldihydrooxazine [D]-7e in the expected allylic and enolether positions (Scheme 2, eq 5).

With all of these results in hand, the labeling studies would strongly support the initial mechanistic hypothesis shown in Scheme 3. The starting complex $\mathrm{Cp} * \mathrm{RuCl}(\mathrm{cod})$ easily loses its cod ligand in the presence of $\mathrm{TMSCHN}_{2}$ and alkynals/alkynones, thus leading to ruthenium carbene species $\mathbf{I}$. Oxidative coupling to ruthenacyclobutene followed by ring opening would lead to the $\mathrm{Ru}$ vinyl carbene II (for diastereoselectivity purposes, carbenes leading to $\mathbf{2} \mathbf{g}$ and $\mathbf{2} \mathbf{m}$ are shown). ${ }^{[10]}$

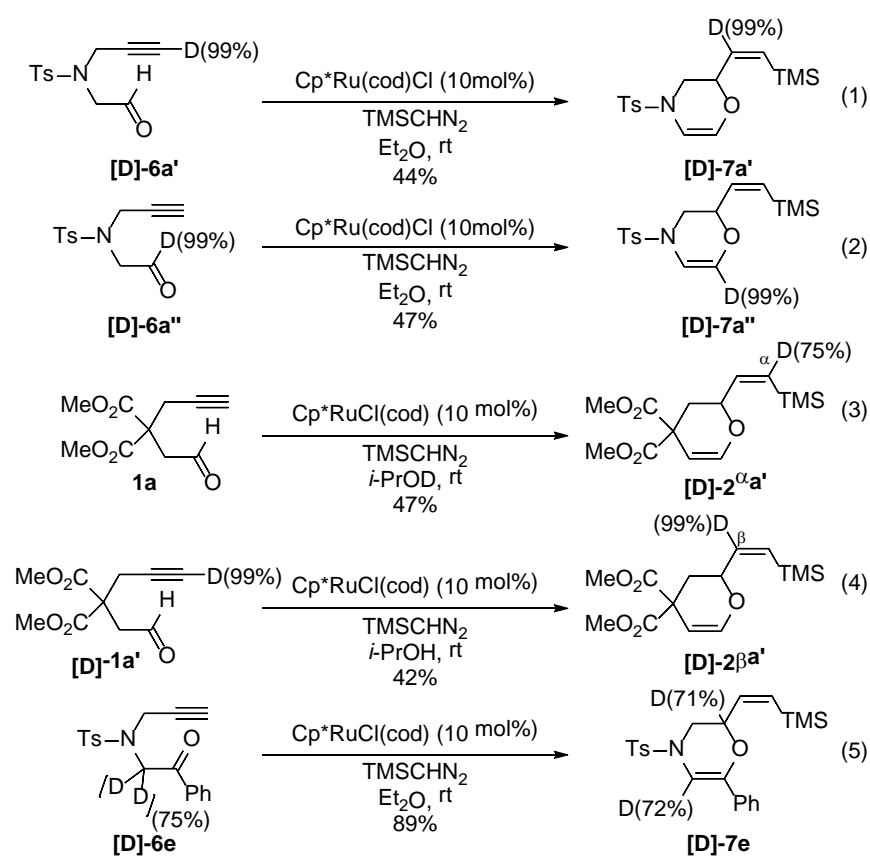

Scheme 2. Deuterium labeling experiments.

The electrophilic Ru carbene could induce a nucleophilic attack by the carbonyl group to afford the zwitterionic intermediate III. Finally, deprotonation and re-protonation of $\mathrm{C}-\mathrm{Ru}$ bond will generate the observed 2-vinyldihydropyrans with recovery of the catalytic Ru carbene in the presence of TMSCHN2. Direct attack of C-Ru bond onto the oxacarbenium ion III will produce the minor vinyloxirane 3a. Diastereoselectivity seems to be controlled by the chair-like conformer of the vinyl Ru carbene intermediate $\mathbf{I I}_{a}$ with all substituents in equatorial positions. The lower diastereoselectivity found in alkynal $\mathbf{1 g}(\mathrm{R}=\mathrm{H})$ could derive from the equilibrium between the two chair-like structures $\mathbf{I I}_{a}$ and $\mathbf{I I}_{b}$ in which the oxygenated substituent could coordinate to the ruthenium. If this coordination is hampered by the carbonyl substituent, as in phenyl ketone $2 \mathrm{~m}(\mathrm{R}=\mathrm{Ph})$, complete diastereoselectivity is recovered by the prevalence of conformer $\mathbf{I} I_{a}$. On the other hand, deuteration of $\mathrm{TMSCHN}_{2}$ in $i$-PrOD followed by deprotonation could generate variable amounts of $\mathrm{TMSCDN}_{2}$ and this would explain the formation of deuterated $\mathbf{D}-2 \mathbf{a}^{\prime}$ from alkynal $\mathbf{1 a}$ (eq 1). ${ }^{[17]}$

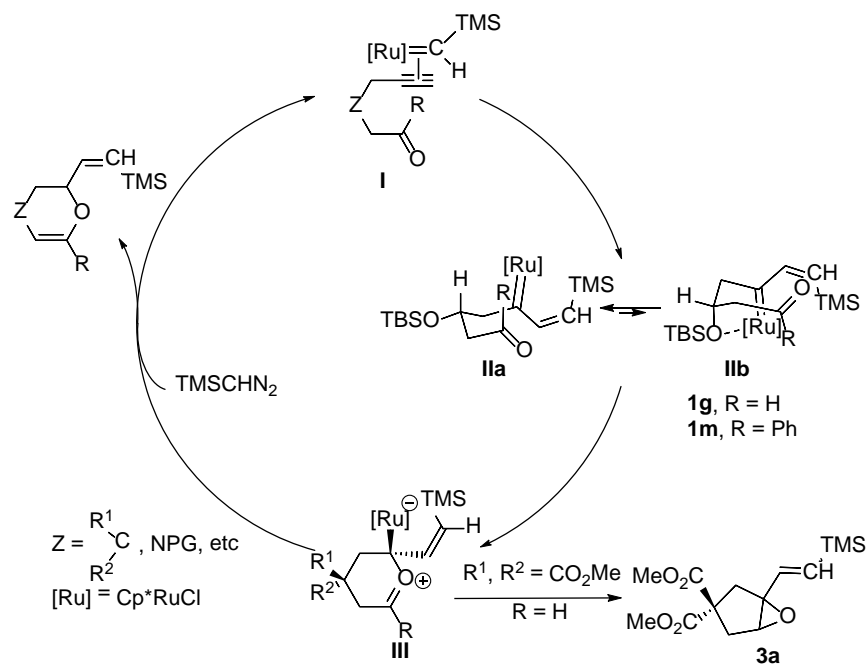


To demonstrate the synthetic utility of the products, we further investigated different reactions to functionalize selectively both double bonds (Scheme 4). Firstly, acetalization of the vinyl ether of 2a occurred smoothly under acidic conditions to give tetrahydropyranyl ether $\mathbf{8}$ in $65 \%$ yield as a mixture of diastereomers (eq 1). ${ }^{[18}$ ] Secondly, in situ formation of desilylated 2vinyldihydropyran $\mathbf{2} \mathbf{k}^{\prime}$ followed by cross-metathesis with styrene afforded the trans- $\beta$-(dihydropyranyl)styrene $\mathbf{9}$ in a good overall yield (eq 2). ${ }^{[19]}$
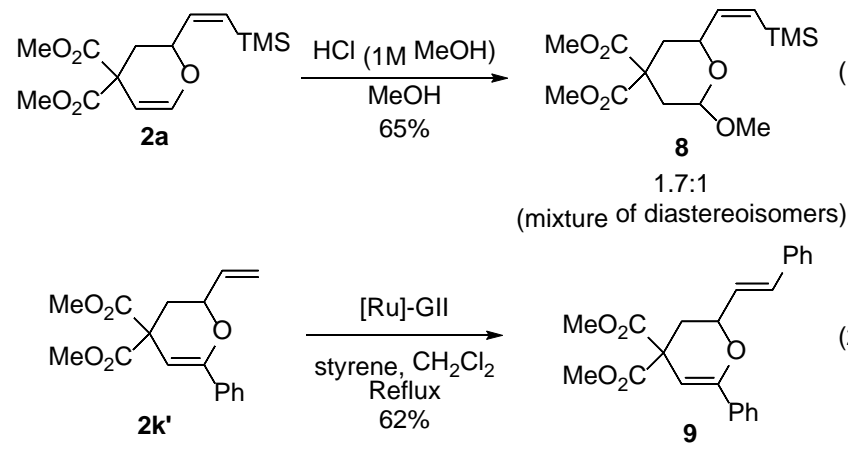

Scheme 4. Reactivity of 2-vinyldihydropyrans 2 .

In conclusion, we have developed a novel synthesis of 2-vinyl dihydropyrans and dihydrooxazines from readily available alkynals and alkynones via Ru(II)-catalyzed cyclizations. Vinyl Ru carbenes derived from alkynes and $\mathrm{TMSCHN}_{2}$ are proposed as the key intermediates of the cyclization processes. Dihydropyrans and dihydrooxazines were obtained in moderate-to-high yields under mild reaction conditions with good functional group tolerance and these could be further transformed into a variety of important derivatives. Further mechanistic studies and enantioselective applications are underway in our laboratory.

Received: ((will be filled in by the editorial staff))

Published online on ((will be filled in by the editorial staff))

Keywords: alkynyl derivatives $\bullet$ carbenes $\bullet$ cyclization $\bullet$ pyrans • ruthenium

[1] B. W. Fravel, in Pyrans and their Benzo Derivatives: Applications in Comprehensive Heterocyclic Chemistry III, Vol. 7 (Eds: A. R. Katritzky, C. A. Ramsden, E. F. V. Scriven, R. J. K. Taylor), Elsevier, 2008, pp 701-726.

[2] For a review, see: I. Larrosa, P. Romea, F. Urpi, Tetrahedron 2008, 64 , 2683-2723.

[3] For a compilation, see: P. Clarke, Ed. Tetrahedron 2011, 67, 49495124.

[4] a) P. H. Seeberger, M. T. Bilodeau, S. J. Danishefsky, Aldrichimica Acta 1997, 30, 75-92. b) N. G. Ramesh, K. K. Balasubramanian, Eur. J. Org. Chem. 2003, 4477-4487. c) R. R. Schmidt, Y. D. Vankar, Acc. Chem. Res. 2008, 41, 1059-1073. d) J. T. Smoot, A. V. Demchenko, Adv. Carbohydr. Chem. Biochem. 2009, 62, 161-250. e) T. J. Boltje, T. Buskas, G.-J. Boons, Nat. Chem. 2009, 1, 611-622.
[5] a) P. Sears, C.-H. Wong, Science 2001, 291, 2344-2350. b) K. C. Nicolaou, H. J. Mitchell, Angew. Chem. 2001, 113, 1624-1672. Angew. Chem. Int. Ed. 2001, 40, 1576-1624. c) B.Yu, L.-X Wang, S. Danishefsky, D. Crich, in Carbohydrate synthesis towards Glycobiology (Eds: K. Ding, L.-X. Dai), Wiley-VCH, 2012.

[6] a) S. Danishefsky, E. Larson, D. Askin, N. Kato, J. Am. Chem. Soc. 1985, 107, 1246-1255. For a recent application, see: b) B. Zhao, T.-P. Loh, Org. Lett. 2013, 15, 2914-2917.

[7] For W: a) F. E. McDonald, K. S. Reddy, Y. Diaz, J. Am. Chem. Soc. 2000, 122, 4304-4309. For Rh: b) B. M. Trost, Y. H. Rhee, J. Am. Chem. Soc. 2003, 125, 7482-7483. For Ru: c) B. M. Trost, Y. H. Rhee, J. Am. Chem. Soc. 2002, 124, 2528-2533. d) A. Varela-Fernández, C. González-Rodríguez, J. A. Varela, L. Castedo, C. Saá, Org. Lett. 2009 11, 5350-5353. e) P. N. Liu, F. H. Su, T. B. Wen, H. H. Y. Sung, I. D. Williams, G. Jia, Chem. Eur. J. 2010, 16, 7889-7897. For metal vinylidenes in synthesis, see: f) Metal Vinylidenes and Allenylidenes in Catalysis: From Reactivity to Applications in Synthesis (Eds: C. Bruneau, P. H. Dixneuf), Wiley-VCH, Winheim, 2008.

[8] For Pd: a) B. M. Trost, A. J. Frontier, J. Am. Chem. Soc. 2000, 122, 11727-11728. b) N. Asao, T. Nogami, K. Takahashi, Y. Yamamoto, J. Am. Chem. Soc. 2002, 124, 764-765. c) N. T. Patil, L. M. Lutete, H. Wu, N. K. Pahadi, I. D. Gridnev, Y. Yamamoto, J. Org. Chem. 2006, 71, 4270-4279. d) F. Silva, M. Reiter, R. Mills-Webb, M. Sawicki, D. Klär, N. Bensel, A. Wagner, V. Gouverneur, J. Org. Chem. 2006, 71, 8390-8394. For Ir: e) X. Li, A. R. Chianese, T. Vogel, R. H. Crabtree, Org. Lett. 2005, 7, 5437-5440. For Au: f) Z. Zhang, C. Liu, R. E. Kinder, X. Han, H. Qian, R. A. Widenhoefer, J. Am. Chem. Soc. 2006, 128, 9066-9073. g) A. S. K. Hashmi, S. Schäfer, M. Wölfle, C. Diez Gil, P. Fischer, A. Laguna, M. C. Blanco, M. C. Gimeno, Angew. Chem. 2007, 119, 6297-6300. Angew. Chem. Int. Ed. 2007, 46, $6184-$ 6187. h) G. L. Hamilton, E. J. Kang, M. Mba, F. D. Toste, Science 2007, 317, 496-499. For Au-catalyzed 6-endo cycloisomerization of $\beta$-hydroxyallenes to 5,6-dihydropyrans, see: i) B. Gockel, N. Krause, Org. Lett. 2006, 8, 4485-4488. For Fe: j) A. Guérinot, A. Serra-Muns, C. Bensoussan, S. Reymond, J. Cossy, Tetrahedron 2011, 67, 50245033.

[9] For an elegant enantioselective synthesis of 2- and 3-alkenyl-3,4dihydropyrans from prefunctionalized enolethers, see: A.-L. Lee, S. J. Malcolmson, A. Puglisi, R. R. Schrock, A. H. Hoveyda, J. Am. Chem. Soc. 2006, 128, 5153-5157.

[10] a) J. Le Paih, S. Dérien, I. Özdemir, P. H. Dixneuf, J. Am. Chem. Soc. 2000, 122, 7400-7401. b) F. Monnier, D. Castillo, S. Dérien, L. Toupet, P. H. Dixneuf, Angew. Chem. 2003, 115, 5632-5635. Angew. Chem. Int. Ed. 2003, 42, 5474-5477. c) R. Morita, E. Shirakawa, T. Tsuchimoto, Y. Kawakami, Org. Biomol. Chem. 2005, 3, 1263-1268. d) F. Monnier, B. C. Vovard-Le, D. Castillo, V. Aubert, S. Derien, P. H. Dixneuf, L. Toupet, A. Ienco, C. Mealli, J. Am. Chem. Soc. 2007, 129, 6037-6049. e) B. C. Vovard-Le, S. Derien, P. H. Dixneuf, C. R. Chim. 2010, 13, 292-303. For synthetic applications of metal carbenes, see: F. Zaragoza, in Metal Carbenes in Organic Synthesis, WileyVCH, 2008.

[11] For catalytic Ru carbene insertion into Csp3-H bonds, see: F. Cambeiro, S. López, J. A. Varela, C. Saá, Angew. Chem. 2012, 124, 747-751. Angew. Chem. Int. Ed. 2012, 51, 723-727.

[12] Other $\mathrm{Ru}(\mathrm{II})$ catalysts as $\mathrm{Cp} * \mathrm{RuCl}\left(\mathrm{PPh}_{3}\right)_{2},\left[\mathrm{RuCl}_{2}(p \text {-cymene) }]_{2}\right.$, and Grubbs carbene ( $2^{\text {nd }}$ generation) were unreactive in $\mathrm{Et}_{2} \mathrm{O}$ at rt.

[13] A very low yield of the corresponding dihydropyran 2 was obtained when diazoester EtOOCCHN $\mathrm{N}_{2}$ (3 equiv) was employed in dioxane at $100^{\circ} \mathrm{C}$.

[14] The corresponding vinyl epoxide 3 has not been detected by GCMS.

[15] a) H. Brice, D. M. Gill, L. Goldie, P. S. Keegan, W. J. Kerr, P. H. Svensson, Chem. Commun. 2012, 48, 4836-4838. b) R. Bogacki, D. M. Gill, W. J. Kerr, S. Lamont, J. A. Parkinson, L. C. Paterson, Chem. Commun. 2013, 49, 8931-8933.

[16] For TBAF desilylations of dihydropyrans and dihydrooxazines, see SI.

[17] Coordinating solvents $\left(\mathrm{Et}_{2} \mathrm{O}, i-\mathrm{PrOH}\right)$ could help to stabilize unsaturated ruthenium species formed during the catalytic cycle.

[18] S. Negishi, H. Ishibashi, J.-i. Matsuo, Org. Lett. 2010, 12, 4984-4987.

[19] K. Lee, H. Kim, J. Hong, Org. Lett. 2009, 11, 5202-5205. 


\section{Angewandte}

\section{Homogeneous catalysis}

Fermín Cambeiro, Susana López, Jesús

A. Varela, Carlos Saá*

Page - Page

Vinyl Dihydropyrans and

Dihydrooxazines from Cyclizations of

Catalytic Ruthenium Carbenes Derived

from Alkynals and Alkynones

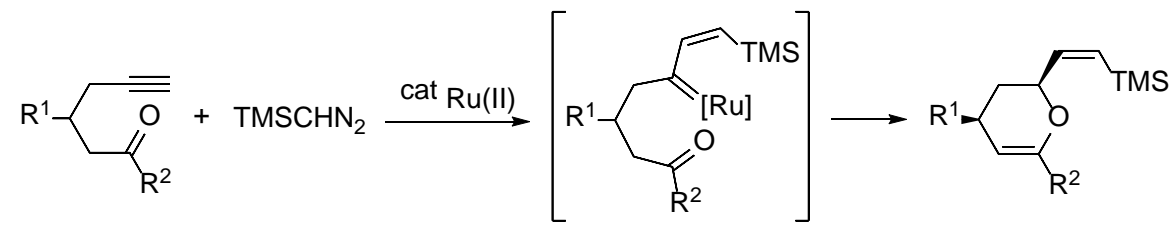

A novel synthesis of 2-vinyl dihydropyrans and dihydro-1,4-oxazines (morpholine derivatives) from alkynals and alkynones has been developed. The cyclizations require a mild generation of catalytic ruthenium carbenes from terminal alkynes and (trimethylsilyl)diazomethane followed by trapping with carbonyl nucleophiles. Mechanistic aspects of the new cyclizations are discussed. 